\title{
Interaction of platelet-derived growth factor with thrombospondin 1
}

\author{
Philip J. HOGG'1 Kylie A. HOTCHKISS, Barbara M. JIMÉNEZ, Paul STATHAKIS and Colin N. CHESTERMAN \\ Centre for Thrombosis and Vascular Research, School of Pathology and Department of Haematology, Prince of Wales Hospital, University of New South Wales, \\ Sydney, NSW 2052, Australia
}

Key factors that mediate vascular smooth muscle cell proliferation and migration are platelet-derived growth factor (PDGF) and thrombospondin 1 (TSP1). We now report that $\mathrm{PDGF}_{\mathrm{BB}}$ bound tightly and specifically to TSP1, that this interaction was markedly dependent on the disulphide bond arrangement in TSP1, and that binding of PDGF ${ }_{\mathrm{BB}}$ to TSP1 did not preclude $\mathrm{PDGF}_{\mathrm{BB}}$ from binding to its receptor on rat aortic vascular smooth-muscle cells. At physiological ionic strength and $\mathrm{pH}, \mathrm{PDGF}_{\mathrm{BB}}$ bound to $\mathrm{Ca}^{2+}$-depleted TSP1 with a dissociation constant of $11 \pm 2 \mathrm{nM}$ and to $\mathrm{Ca}^{2+}$-replete TSP1 with a dissociation constant of $32 \pm 5 \mathrm{nM}$. Binding was specific, as both soluble TSP1 and unlabelled PDGF $_{\mathrm{BB}}$ competed for binding of iodinated PDGF $_{\mathrm{BB}}$ to immobilized TSP1, whereas other platelet $\alpha$-granule proteins did not compete. The tertiary structure of TSP1 is regulated by intramolecular disulphide interchange; we found that catalysis of disulphide interchange in TSP1 by protein disulphide isomerase ablated the binding of $\mathrm{PDGF}_{\mathrm{BB}}$. The interaction of PDGF $_{\mathrm{BB}}$ with TSP1 was weakened by increasing salt concentration and essentially ablated at 0.65 ionic strength; it was inhibited by heparin with a half-maximal effect at 20 i.u./ml, implying that the binding was mediated largely by ionic interactions. An anti TSP1 monoclonal antibody decreased the binding of iodinated $\mathrm{PDGF}_{\mathrm{BB}}$ to $\mathrm{PDGF}$ receptor on rat aortic vascular smooth-muscle cells by $37 \pm 2 \%$, whereas platelet TSP1 non-competitively inhibited binding of iodinated $\mathrm{PDGF}_{\mathrm{BB}}$. Uncomplexed $\mathrm{PDGF}_{\mathrm{BB}}$ bound to PDGF receptor with an affinity $5 \pm 2$ times that of $\mathrm{PDGF}_{\mathrm{BB}}-\mathrm{TSP} 1$ complexes. These results suggest that TSP1 might assist in the targeting of PDGF to its receptor on vascular smooth-muscle cells.

\section{INTRODUCTION}

Platelet-derived growth factor (PDGF) was discovered as a major mitogenic factor in serum, absent from plasma, and was subsequently shown to be secreted from platelet $\alpha$-granules [1-4]. PDGF is produced by many cells, including arterial endothelial and vascular smooth-muscle cells (SMCs), monocyte/macrophages, fibroblasts, and a variety of transformed cells. PDGF is a potent mitogen for fibroblasts, glial cells, arterial SMCs and some epithelial and endothelial cells, and is also chemotactic for fibroblasts, SMCs, neutrophils and mononuclear cells. PDGF is a dimer of two possible polypeptide chains, $\mathrm{A}$ and $\mathrm{B}$, and interacts with two distinct PDGF receptors on cell surfaces. PDGF has been implicated in a variety of normal and pathological processes, including wound healing, nerve regeneration, glial cell proliferation and differentiation, and neoplastic transformation and tumour pathogenesis. In particular, PDGF has been strongly implicated in atherogenesis [5].

Thrombospondins are a family of multidomain glycoproteins from platelets and most normal and transformed cells. Thrombospondin 1 (TSP1), the platelet TSP, is the best studied and most pervasive and has been shown to play an important role in cell-cell and cell-matrix interactions [6-8]. TSP1 is a multidomain $\mathrm{Ca}^{2+}$-sensitive disulphide-bonded trimer with a subunit molecular mass of $150 \mathrm{kDa}$. Most normal and transformed cells in culture, including fibroblasts [9], endothelial cells [10] and SMCs [11] synthesize and secrete TSP1. TSP1 binds to at least four different cell-surface receptors via separate binding motifs [12-15]. TSP1 is a transient component of extracellular matrices in vivo during embryogenesis [16,17], wound repair [18] and in neoplastic tissues [19], and has been proposed to function in tissue development and remodelling, and in neoplasia.

PDGF and TSP1 activities are closely linked in the pathogenesis of atherosclerosis. The atherosclerotic lesion results from various forms of injury to the endothelium and smooth muscle of the artery wall. A hallmark of the disease is uncontrolled migration and proliferation of SMCs, which results in thickening of the vascular wall and contributes to the eventual occlusion of the artery. PDGF is made by most cells in atherosclerotic lesions and is generally considered to be an important factor responsible for the excessive migration and proliferation of SMCs [5]. TSP1 is found in large amounts in atherosclerotic lesions [20] and derives mostly from activated SMCs [21]. TSP1 is expressed as an immediate-early response to PDGF stimulation of cultured SMCs [22]. These findings imply that PDGF and TSP1 colocalize extracellularly in atherosclerotic lesions. Studies with monoclonal anti-TSP1 antibodies to neutralize endogenously produced TSP1 have shown that TSP1 is a requirement for PDGF-mediated proliferation [23] and migration [24] of SMC. Majack et al. [23] reported that five monoclonal antibodies against TSP1 specifically inhibited SMC growth in serum, and presented evidence that cell-surface-associated TSP1 is functionally essential for the proliferation of vascular SMCs. Yabkowitz et al. [24] showed that a monoclonal anti-TSP1 antibody negated PDGF-mediated migration of vascular SMCs, and proposed that TSP1 functions as an autocrine motility factor to modulate SMC migration.

We now report that $\mathrm{PDGF}_{\mathrm{BB}}$ binds tightly and specifically to TSP1. Our results suggest that the interaction of TSP1 with $\mathrm{PDGF}_{\mathrm{BB}}$ might play a role in the targeting of $\mathrm{PDGF}_{\mathrm{BB}}$ to PDGF receptor on vascular SMCs.

\section{EXPERIMENTAL}

\section{Proteins}

TSP1 was purified from human platelet concentrations as described previously [25], with the following modifications. Throm-

Abbreviations used: FGF, fibroblast growth factor; PDGF, platelet-derived growth factor; PDI, human placenta protein disulphide isomerase; SMC smooth-muscle cell; TSP1, human platelet thrombospondin 1.

1 To whom correspondence should be addressed. 
bin used to activate platelets was inactivated with a 4-fold molar excess of D-Phe-Pro-Arg-chloromethane, and leupeptin to $10 \mu \mathrm{M}$ was added to the platelet releasate. Heparin-Sepharose was eluted stepwise with $0.25 \mathrm{M} \mathrm{NaCl}$ before elution of the TSP1 with $0.55 \mathrm{M} \mathrm{NaCl}$. Buffers containing $0.1 \mathrm{mM} \mathrm{CaCl}_{2}$ were used throughout the chromatographic purification of TSP1. On some occasions, buffers containing $2 \mathrm{mM} \mathrm{CaCl}{ }_{2}$ were used. TSP1 was stripped of transforming growth factor $\beta$ as described by MurphyUllrich et al. [26]. TSP1 concentration was determined with a value of 10.9 for $A_{1 \mathrm{~cm}, 280}^{1 \%}$ and a molecular mass of $450 \mathrm{kDa}$. Human platelet factor 4 and $\beta$-thromboglobulin were purified from human platelet concentrates along with TSP1. Platelet factor 4 was eluted from the heparin-Sepharose column with $2 \mathrm{M} \mathrm{NaCl}$, whereas $\beta$-thromboglobulin eluted after TSP1 on the Bio-Gel A0.5m (Bio-Rad Laboratories, Hercules CA, U.S.A.) gel-filtration column. Fibrinogen [27] and $\alpha_{2}$-macroglobulin [28] were purified from human plasma. Protein disulphide isomerase (PDI) was purified from human placenta as described previously [29]. Proteins were homogeneous as judged by SDS/PAGE. Human recombinant $\mathrm{PDGF}_{\mathrm{AA}}$ (short form) and $\mathrm{PDGF}_{\mathrm{BB}}$ homodimers and transforming growth factor $\beta$ were purchased from Genzyme Diagnostics (Cambridge, MA, U.S.A.). Human recombinant ${ }^{125} \mathrm{I}_{-} \mathrm{PDGF}{ }_{\mathrm{BB}}$ homodimer $(1210 \mathrm{kBq} / \mathrm{mg})$ was from $\mathrm{Du}$ Pont (Sydney, Australia). The monoclonal antibodies used herein were purified from mouse ascites fluid by affinity chromatography on Protein G-Sepharose (Pharmacia, Uppsala, Sweden) in accordance with the manufacturer's instruction. Protein Aagarose beads and GSH were from Sigma-Aldrich, NSW, Australia. All proteins were divided into aliquots and stored at $-80^{\circ} \mathrm{C}$ until use.

\section{Binding of ${ }^{125} \mathrm{I}-\mathrm{PDGF} \mathrm{BB}_{\mathrm{BB}}$ to TSP1}

TSP1 [100 $\mu$ l of $10 \mu \mathrm{g} / \mathrm{ml}$ in $20 \mathrm{mM}$ Hepes (pH 7.4)/0.14 M $\mathrm{NaCl} / 2 \mathrm{mM}$ EDTA $/ 0.02 \% \mathrm{NaN}_{3}$ ] was adsorbed to NuncImmuno BreakApart polystyrene wells (Nunc InterMed, Roskilde, Denmark) overnight at $4{ }^{\circ} \mathrm{C}$ in a humid environment. The wells were washed once with PBS containing $0.05 \%$ Tween-20, non-specific binding sites were blocked by adding $200 \mu \mathrm{l}$ of $2 \%$ (w/v) BSA in PBS and incubating for $90 \mathrm{~min}$ at $37^{\circ} \mathrm{C}$, and then washed three times with binding buffer [20 mM Hepes (pH 7.4) $/ 0.134 \mathrm{M} \mathrm{NaCl} / 2 \mathrm{mM} \mathrm{CaCl}{ }_{2}$ or $2 \mathrm{mM}$ EDTA $/ 0.05 \%$ Tween-20]. ${ }^{125} \mathrm{I}_{-} \mathrm{PDGF}_{\mathrm{BB}}$ in the presence or absence of various competing proteins, heparin or $\mathrm{NaCl}$ was added to wells to a total volume of $100 \mu \mathrm{l}$ in binding buffer and incubated for $30 \mathrm{~min}$ at room temperature on an orbital shaker. This incubation time was determined to be sufficient for the binding interactions to reach equilibrium. Wells were washed three times with binding buffer, separated and counted for radioactivity with a Packard Crystal II $\gamma$-radiation counter. Non-specific binding of ${ }^{125} \mathrm{I}$ $\mathrm{PDGF}_{\mathrm{BB}}$ to control wells not coated with TSP1 but blocked with $2 \%(\mathrm{w} / \mathrm{v}) \mathrm{BSA}$ in PBS represented no more than $20 \%$ of the total binding in all experiments.

\section{Effect of PDI-catalysed disulphide interchange in TSP1 on binding of ${ }^{125}$ I-PDGF}

TSP1 was adsorbed to Nunc-Immuno BreakApart polystyrene wells as described above and incubated with either $20 \mathrm{mM}$ Hepes (pH 7.4)/0.134 M NaCl alone, buffer containing GSH, buffer containing PDI, or buffer containing GSH and PDI for $60 \mathrm{~min}$ at $37^{\circ} \mathrm{C}$. The GSH and PDI concentrations were $0.7 \mathrm{mM}$ and $180 \mathrm{nM}$ respectively. The buffer contained either $2 \mathrm{mM}$ EDTA or $2 \mathrm{mM} \mathrm{Ca}^{2+}$. Binding of ${ }^{125} \mathrm{I}_{-} \mathrm{PDGF}_{\mathrm{BB}}$ to the treated TSP1 was measured as described above.

\section{Calculation of the dissociation constant for the interaction of PDGF $_{88}$ with immobilized TSP1}

Competition for the binding of ${ }^{125} \mathrm{I}_{-}-\mathrm{PDGF}_{\mathrm{BB}}$ to immobilized TSP1 by soluble PDGF $_{\mathrm{BB}}$ was performed to calculate the dissociation constant for the interaction of PDGF $_{\mathrm{BB}}$ with TSP1. The dissociation constants for the interaction of ${ }^{125} \mathrm{I}$ $\operatorname{PDGF}_{\mathrm{BB}}\left(K_{\mathrm{H}}\right)$ or $\mathrm{PDGF}_{\mathrm{BB}}\left(K_{\mathrm{C}}\right)$ with plastic-adsorbed TSP1 are described by:

$$
\left.\begin{array}{rl}
K_{\mathrm{H}} & =[\mathrm{H}][\mathrm{T}] /[\mathrm{HT}] \\
K_{\mathrm{C}} & =[\mathrm{C}][\mathrm{T}] /[\mathrm{CT}] \\
{[\mathrm{T}]_{0}} & =[\mathrm{T}]+[\mathrm{HT}]+[\mathrm{CT}]
\end{array}\right\}
$$

$[\mathrm{T}],[\mathrm{H}]$ and $[\mathrm{C}]$ are the concentrations of free immobilized TSP1binding sites, ${ }^{125} \mathrm{I}_{-\mathrm{PDGF}}$ ${ }_{\mathrm{BB}}$ and $\mathrm{PDGF}_{\mathrm{BB}}$, and [HT] and [CT] are the concentrations of ${ }^{125} \mathrm{I}_{-\mathrm{PDGF}}{ }_{\mathrm{BB}}$-immobilized TSP1 and $\mathrm{PDGF}_{\mathrm{BB}}$-immobilized TSP1 complexes respectively. The subscript 0 denotes total reactant concentration. If the total concentration of $\mathrm{PDGF}_{\mathrm{BB}}$ in the experiment is at least 10 times the concentration of $\mathrm{PDGF}_{\mathrm{BB}}$-immobilized TSP1 complex, $[\mathrm{C}]_{0} \geqslant$ $10[\mathrm{CT}]$, then $[\mathrm{C}]_{0} \approx[\mathrm{C}]$ and an expression for $[\mathrm{HT}]$ in terms of the constants $K_{\mathrm{H}}, K_{\mathrm{C}},[\mathrm{T}]_{0},[\mathrm{H}]_{0}$ and $[\mathrm{C}]_{0}$ can be derived from eqn. (1). This approach and a similar derivation have been described by Olson et al. [30]. Eqn. (2) is a quadratic in [HT]:

$$
[\mathrm{HT}]^{2} K_{\mathrm{C}}-[\mathrm{HT}]\left\{K_{\mathrm{C}}\left([\mathrm{T}]_{0}+[\mathrm{H}]_{0}+K_{\mathrm{H}}[\mathrm{C}]_{0}\right\}+[\mathrm{T}]_{0}[\mathrm{H}]_{0} K_{\mathrm{C}}=0\right.
$$

The characterization of the binding system is in two parts. First, the affinity of ${ }^{125} \mathrm{I}_{-\mathrm{PDGF}} \mathrm{BB}_{\mathrm{B}}$ for immobilized TSP1, $K_{\mathrm{H}}$, is estimated from experiments that measure the binding of a range of ${ }^{125}$ I-PDGF $_{\mathrm{BB}}$ concentrations to a fixed concentration of immobilized TSP1 (see Figure 1a). Secondly, the affinity of PDGF ${ }_{\text {вв }}$ for immobilized TSP1, $K_{\mathrm{C}}$, is estimated from experiments that measure the binding of a fixed concentration of ${ }^{125} \mathrm{I}_{-\mathrm{PDGF}} \mathrm{BB}$ to immobilized TSP1 as a function of PDGF ${ }_{\mathrm{BB}}$ concentration (see Figure 1b). Data were fitted to eqns. (1) and (2) by non-linear least-squares regression (Scientist software; Micromath, Salt Lake City, UT, U.S.A.).

\section{Calculation of the dissociation constant for the interaction of ${ }^{125}$ I-PDGF $_{\mathrm{BB}}$ with soluble TSP1}

To calculate the affinity of ${ }^{125}$ I-PDGF $_{\mathrm{BB}}$ for soluble TSP1 we used a competitive binding assay that has been described previously [30,31]. The dissociation constant for the binding of ${ }^{125} \mathrm{I}_{-} \mathrm{PDGF}{ }_{\mathrm{Bв}}$ to TSP1 is estimated from the ability of soluble TSP1 to compete for binding of ${ }^{125} \mathrm{I}_{-} \mathrm{PDGF} \mathrm{BB}_{\mathrm{BB}}$ to plastic-adsorbed TSP1. The dissociation constants for the interaction of ${ }^{125} \mathrm{I}-$ $\mathrm{PDGF}_{\mathrm{BB}}$ with plastic-adsorbed TSP1 $\left(K_{\mathrm{H}}\right)$ and soluble TSP1 $\left(K_{\mathrm{S}}\right)$ are:

$$
\left.\begin{array}{rl}
K_{\mathrm{H}} & =[\mathrm{H}][\mathrm{T}] /[\mathrm{HT}] \\
K_{\mathrm{S}} & =[\mathrm{H}][\mathrm{S}] /[\mathrm{HS}] \\
{[\mathrm{T}]_{0}} & =[\mathrm{T}]+[\mathrm{HT}]+[\mathrm{HS}]
\end{array}\right\}
$$

$[\mathrm{T}],[\mathrm{H}]$ and $[\mathrm{S}]$ are the concentrations of free immobilized TSP1binding sites, ${ }^{125} \mathrm{I}_{-\mathrm{PDGF}} \mathrm{BB}_{\mathrm{BB}}$ and soluble TSP1-binding sites, and $[\mathrm{HT}]$ and $[\mathrm{HS}]$ are the concentrations of ${ }^{125} \mathrm{I}_{-\mathrm{PDGF}} \mathrm{BB}$-immobilized TSP1 and ${ }^{125} \mathrm{I}_{-\mathrm{PDGF}} \mathrm{BB}$-soluble TSP1 complexes respectively. If the total concentration of soluble TSP1 in the experiment is at least 10 times the concentration of ${ }^{125} \mathrm{I}_{-} \mathrm{PDGF}_{\mathrm{BB}^{-}}$ soluble TSP1 complex, $[\mathrm{S}]_{0} \geqslant 10[\mathrm{HS}]$, then $[\mathrm{S}]_{0} \approx[\mathrm{S}]$ and an expression for $[\mathrm{HT}]$ in terms of the constants $K_{\mathrm{H}}, K_{\mathrm{S}},[\mathrm{T}]_{0},[\mathrm{H}]_{0}$ and $[\mathrm{S}]_{0}$ can be derived from eqn. (3) [30]. Eqn. (4) is a quadratic in $[\mathrm{HT}]$ :

$$
[\mathrm{HT}]^{2}-[\mathrm{HT}]\left\{[\mathrm{H}]_{0}+[\mathrm{T}]_{0}+K_{\mathrm{H}}+K_{\mathrm{H}} /\left(K_{\mathrm{S}}[\mathrm{S}]_{0}\right)\right\}+[\mathrm{H}]_{0}[\mathrm{~T}]_{0}=0
$$

The affinity of ${ }^{125}$ I-PDGF $_{\mathrm{BB}}$ for soluble TSP1 is estimated from experiments that measure the binding of a fixed concentration of ${ }^{125} \mathrm{I}_{-}-\mathrm{PDGF}{ }_{\mathrm{BB}}$ to immobilized TSP1 as a function of soluble TSP1 


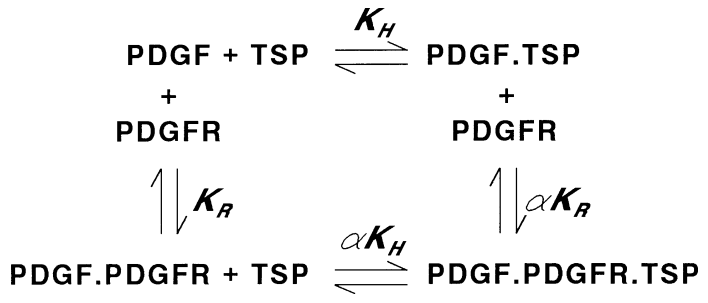

Scheme 1 Model for the non-competitive inhibition of binding of PDGF $_{B \mathrm{~B}}$ to its receptor on SMC by TSP1

PDGF interacts with TSP1 with a dissociation constant $K_{\mathrm{H}}$, and with PDGF receptor on SMCs (PDGFR) with a dissociation constant $K_{R}$. The model states that both PDGF and PDGF.TSP interact with PDGFR, but the binding of PDGF.TSP is weakened by a factor $\alpha$. Because of the linked equilibria of this model, TSP must also interact with PDGF.PDGFR with a dissociation constant a. $K_{\mathrm{H}}$.

concentration (see Figure 2). Importantly, the estimate of the affinity of ${ }^{125} \mathrm{I}_{-}-\mathrm{PDGF}_{\mathrm{BB}}$ for soluble TSP1 is independent of the mechanism of binding attributed to the interaction of ${ }^{125} \mathrm{I}$ PDGF $_{\mathrm{BB}}$ with immobilized TSP1 [31]. Data were fitted to eqns. (3) and (4) by non-linear least-squares regression.

\section{Binding of ${ }^{125} \mathrm{I}-\mathrm{PDGF}_{\mathrm{BB}}$ to PDGF receptor on rat aortic SMCs}

Aortic SMCs from adult Wistar rats were a gift from Dr. Peter Little (Baker Medical Research Institute, Melbourne, Australia) [32]. Binding of ${ }^{125} \mathrm{I}_{-\mathrm{PDGF}} \mathrm{BB}_{\mathrm{BB}}$ to cultured rat aortic SMCs was measured as described by Bowen-Pope and Ross [33]. Nonspecific binding was determined by using $0.6 \mathrm{nM}$ or $20 \mathrm{ng} / \mathrm{ml}$ unlabelled $\mathrm{PDGF}_{\mathrm{BB}}$, approx. 40 times the dissociation constant, and subtracted from the total binding. Non-specific binding represented no more than $15 \%$ of the total binding in all experiments. The effect of unlabelled $\mathrm{PDGF}_{\mathrm{BB}}$, TSP1, murine anti-TSP1 monoclonal antibody HB8432 [9] and $\alpha_{2}$-macroglobulin on the binding of ${ }^{125} \mathrm{I}_{-} \mathrm{PDGF} \mathrm{BB}_{\mathrm{BB}}$ to PDGF receptor was determined. HB8432 monoclonal antibody and a control monoclonal antibody generated against bovine liver PDI were used at a final concentration of $100 \mu \mathrm{g} / \mathrm{ml}$.

\section{Analysis of the non-competitive inhibition of binding of $\mathrm{PDGF}_{\mathrm{BB}}$ to rat aortic SMCs by TSP1}

The effect of TSP1 on binding of labelled PDGF ${ }_{\mathrm{BB}}$ to rat aortic SMCs has been fitted to the model described in Scheme 1. In this model, ${ }^{125} \mathrm{I}_{-} \mathrm{PDGF}_{\mathrm{BB}}(\mathrm{H})$ interacts with TSP1 (T) with dissociation constant $K_{\mathrm{H}}$, and with PDGF receptor on SMCs (R) with a dissociation constant $K_{\mathrm{R}}$. The model states that both $\mathrm{H}$ and HT interact with R, but the binding of HT is weakened by a factor $\alpha$. Because of the linked equilibria of this model, T must also interact with HR with a dissociation constant $\alpha K_{\mathrm{H}}$. This model is described by eqn. (5):

$$
\left.\begin{array}{rl}
{[\mathrm{HT}]} & =\{[\mathrm{H}][\mathrm{T}]\} / K_{\mathrm{H}} \\
{[\mathrm{HR}]} & =\{[\mathrm{H}][\mathrm{R}]\} / K_{\mathrm{R}} \\
{[\mathrm{HRT}]} & =\{[\mathrm{H}][\mathrm{R}][\mathrm{T}]\} /\left(\alpha K_{\mathrm{H}} K_{\mathrm{R}}\right)
\end{array}\right\}
$$

where:

$$
\begin{aligned}
{[\mathrm{H}] } & =[\mathrm{H}]_{0}-[\mathrm{HR}]-[\mathrm{HT}]-[\mathrm{HRT}] \\
{[\mathrm{R}] } & =[\mathrm{R}]_{0}-[\mathrm{HR}]-[\mathrm{HRT}] \\
{[\mathrm{T}] } & =[\mathrm{T}]_{0}-[\mathrm{HT}]-[\mathrm{HRT}]
\end{aligned}
$$

Because $K_{\mathrm{R}}$ and $[\mathrm{R}]_{0}$ are of similar magnitude (low picomolar) under the conditions of our experiments, an explicit relationship in terms of the known total concentrations of $\mathrm{H}$ and $\mathrm{T}$ and the parameters $K_{\mathrm{H}}, K_{\mathrm{R}},[\mathrm{R}]_{0}$ and $\alpha$ cannot be derived. In other words, the usual assumption that the total concentration of ${ }^{125} \mathrm{I}_{-\mathrm{PDGF}}$ will be a good approximation of the free concentration of ${ }^{125} \mathrm{I}-$ $\mathrm{PDGF}_{\mathrm{BB}}$ is not valid in our binding system. Therefore eqn. (5) was fitted to the data by numerical integration with a leastsquares minimization procedure (Scientist software; Micromath).

\section{RESULTS}

\section{Interaction of PDGF $_{\mathrm{BB}}$ with TSP1}

The interaction of ${ }^{125}{ }^{-}-\mathrm{PDGF}_{\mathrm{BB}}$ with $\mathrm{TSP} 1$ in solution was measured with a competitive binding technique. In this technique, TSP1 immobilized on polystyrene was used as a probe to monitor the solution-phase binding of ${ }^{125} \mathrm{I}_{-}-\mathrm{PDGF}_{\mathrm{BB}}$ to TSP1. Interaction of ligands with protein acceptors immobilized on plastic often introduces artifacts due to varying degrees of denaturation of the plastic-bound protein. Therefore it was important to characterize
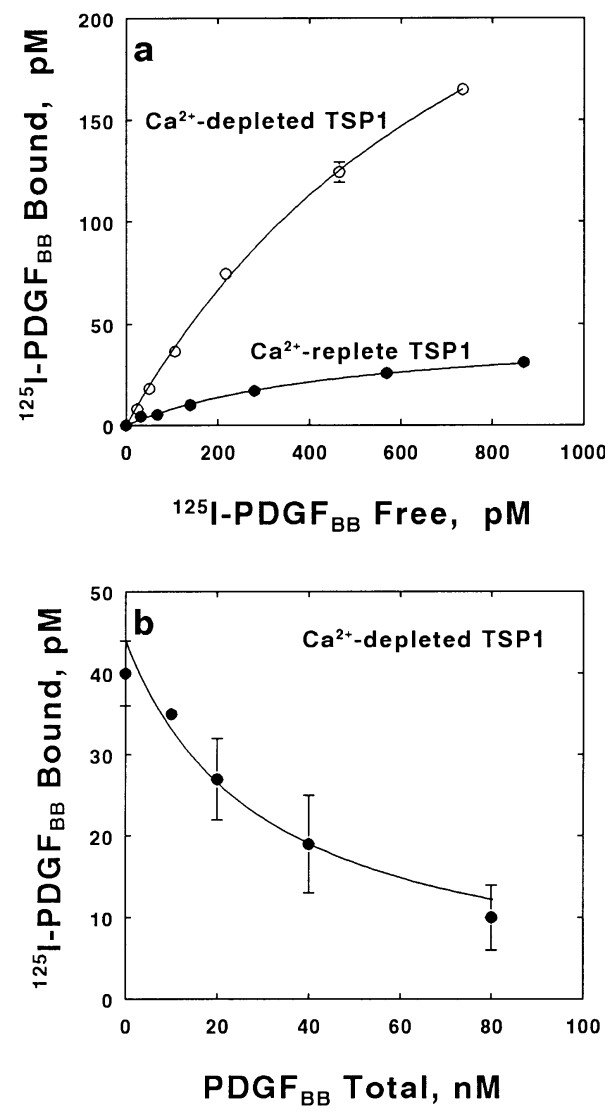

Figure 1 Binding of PDGF $_{B B}$ to immobilized TSP1

(a) Binding of ${ }^{125} \mathrm{I}_{-\mathrm{PDGF}}$ to immobilized $\mathrm{Ca}^{2+}$-depleted $(\mathrm{O})$ or $\mathrm{Ca}^{2+}$-replete $(\mathbf{O})$ TSP1. The solid lines represent the best fit of the data to a single rectangular hyperbola with dissociation constant and maximal number of binding sites of $0.90 \pm 0.19 \mathrm{nM}$ and $0.37 \pm 0.06 \mathrm{nM}$ for

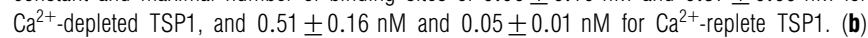
Competition for binding of ${ }^{125} \mathrm{I}-\mathrm{PDGF} \mathrm{BB}_{\mathrm{BB}}$ to immobilized $\mathrm{Ca}^{2+}$-depleted TSP1 by soluble PDGF ${ }_{\mathrm{BB}}$. The total concentration of ${ }^{125}{ }_{-P D G F}$ in the experiment was $150 \mathrm{pM}$. The solid line represents the best fit of the data to eqn. (2) with a dissociation constant for binding of $\mathrm{PDGF}_{\mathrm{BB}}$ to immobilized TSP1, $K_{\mathrm{H}}$, of $20 \pm 6 \mathrm{nM}$. Other parameters in eqn. (2) were as estimated in (a) and listed in Table 1. The error bars in (a) and (b) represent the ranges of duplicate experiments. 

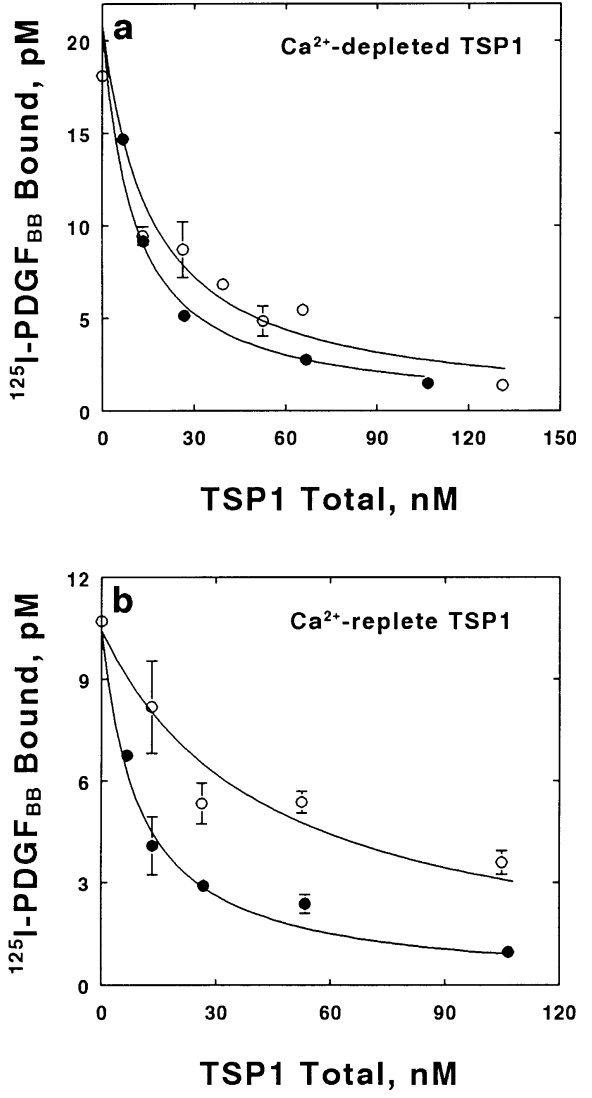

Figure 2 Binding of ${ }^{125}$ I-PDGF $_{\mathrm{BB}}$ to soluble TSP1

(a) Competition of binding of ${ }^{125}{ }_{\text {-PDGF }}$ to immobilized TSP1 by soluble TSP1 $(O)$ or stripped TSP1 (-). TSP1 was $\mathrm{Ca}^{2+}$-depleted. The total concentration of ${ }^{125}{ }_{-}-\mathrm{PDGF}_{\mathrm{BB}}$ in the experiment was $75 \mathrm{pM}$. The solid lines have been drawn by using eqns. (3) and (4) and the dissociation constants for binding of ${ }^{125} \mathrm{I}-\mathrm{PDGF}_{\mathrm{BB}}$ to $\mathrm{Ca}^{2+}$-depleted plastic-immobilized TSP1 (Figure 1) and the soluble TSP1s (Table 1). (b) Competition for binding of 125 - PDGF $_{B B}$ to immobilized TSP1 by soluble TSP1 $(O)$ or stripped TSP1 $(\mathbf{O})$. TSP1 was $\mathrm{Ca}^{2+}$-replete. The total concentration of ${ }^{125}$ - $-\mathrm{PDGF}_{\mathrm{BB}}$ in the experiment was $150 \mathrm{pM}$. The solid lines have been drawn by using eqn. (4) and the dissociation constants listed in Figure 1 and Table 1. The error bars in (a) and (b) represent the range of duplicate experiments.

the interaction of ${ }^{125}{ }^{-}-$PDGF $_{\mathrm{BB}}$ with soluble TSP1. The application of this competitive binding technique and the method of analysis have been described for a variety of binding systems $[30,31,34,35]$. The binding system is in two parts. First the interaction of ${ }^{125} \mathrm{I}_{-} \mathrm{PDGF}_{\mathrm{BB}}$ with immobilized TSP1 was measured.

Binding was measured in $\mathrm{pH} 7.4$ buffer at physiological ionic strength. The binding interactions in this system were reversible (see below) and reached equilibrium in $30 \mathrm{~min}$ (results not shown). The results are shown in Figure 1(a). The binding was characterized by a dissociation constant and maximal number of binding sites of $0.90 \pm 0.19 \mathrm{nM}$ and $0.37 \pm 0.06 \mathrm{nM}$ respectively (means \pm S.D.). To ensure that the binding of radiolabelled PDGF $_{\mathrm{BB}}$ to TSP1 was not an artifact due to iodination, competition for binding of ${ }^{125} \mathrm{I}_{-} \mathrm{PDGF} \mathrm{BB}_{\mathrm{BB}}$ to immobilized TSP1 by soluble PDGF ${ }_{\mathrm{Bв}}$ was measured (Figure 1b). The best fit of the data to eqn. (2) gave a dissociation constant for binding of $\mathrm{PDGF}_{\mathrm{BB}}$ to immobilized TSP1 of $20 \pm 6 \mathrm{nM}$ (mean \pm S.D.) [30]. Therefore iodinated PDGF ${ }_{\mathrm{BB}}$ bound to immobilized TSP1 with an approx. 20-fold tighter affinity than did unlabelled PDGF. The reason for this difference is unknown. When two standard deviations are applied, the dissociation constants are $0.9 \pm 0.4$ $\mathrm{nM}$ for ${ }^{125} \mathrm{I}_{-}-\mathrm{PDGF}_{\mathrm{BB}}$ and $20 \pm 12 \mathrm{nM}$ for $\mathrm{PDGF}_{\mathrm{BB}}$. Therefore
Table 1 Dissociation constants for binding of ${ }^{125} \mathrm{I}_{-\mathrm{PDGF}}$, to different forms of soluble TSP1

Results are means \pm S.D.

\begin{tabular}{lll}
\hline \multirow{2}{*}{ Form of TSP1 } & Ca ${ }^{2+}$ form & Dissociation constant (nM) \\
\hline \multirow{2}{*}{ Native } & Depleted & $11 \pm 2$ \\
\multirow{2}{*}{ 'Stripped' [26] } & Replete & $32 \pm 5$ \\
& Depleted & $7 \pm 2$ \\
& Replete & $7 \pm 2$ \\
\hline
\end{tabular}

the dissociation constants are almost within statistical error. The greatest source of experimental error is probably the specific radioactivity of the iodinated $\mathrm{PDGF}_{\mathrm{BB}}$ and the concentration of the stock unlabelled $\mathrm{PDGF}_{\mathrm{BB}}$, which are supplied and characterized by different manufacturers. Considering these factors, the discrepancy in affinities was not considered significant in the context of the studies and was not pursued further.

Secondly, the dissociation constant for binding of ${ }^{125} \mathrm{I}_{-\mathrm{PDGF}} \mathrm{BB}_{\mathrm{B}}$ to soluble TSP1 was estimated from the ability of soluble TSP1 to compete for binding of ${ }^{125} \mathrm{I}-\mathrm{PDGF}_{\mathrm{BB}}$ to plastic-adsorbed TSP1. An important property of this binding system is that the equilibrium constant measured for the solution-phase interaction is independent of the mechanism ascribed to the binding of the ligand to the immobilized acceptor [34,35]. These results are shown in Figure 2. The binding was measured for $\mathrm{Ca}^{2+}$-depleted or -replete TSP1; the results are listed in Table $1 . \mathrm{Ca}^{2+}$ depleted TSP1 bound ${ }^{125}$ I-PDGF $_{\mathrm{BB}}$ with a dissociation constant of $11 \pm 2 \mathrm{nM}$, whereas $\mathrm{Ca}^{2+}$-replete TSP1 bound ${ }^{125}{ }^{2}-\mathrm{PDGF}_{\mathrm{BB}}$ with a dissociation constant of $32 \pm 5 \mathrm{nM}$. TSP1 was further purified ('stripped') by gel filtration in Tris buffer, $\mathrm{pH}$ approx. 10 , to dissociate any contaminating transforming growth factor $\beta$ [26]. $\mathrm{Ca}^{2+}$-depleted or -replete 'stripped' TSP1 bound ${ }^{125} \mathrm{I}-$ $\mathrm{PDGF}_{\mathrm{BB}}$ with an equivalent dissociation constant of $7 \mathrm{nM}$, which is comparable with the affinity of ${ }^{125} \mathrm{I}_{-\mathrm{PDGF}} \mathrm{BB}_{\mathrm{BB}}$ for untreated TSP1. The alkaline $\mathrm{pH}$ used to strip TSP1 of transforming growth factor $\beta$ probably resulted in some unfolding of the TSP1 protein, which might account for the small perturbation in affinity of the treated TSP1 for PDGF ${ }_{\mathrm{BB}}$. We have shown that transforming growth factor $\beta$ did not displace $\mathrm{PDGF}_{\mathrm{BB}}$ from TSP1 (see below), so PDGF ${ }_{\mathrm{BB}}$ might be expected to bind both untreated and 'stripped' TSP1 with equivalent affinity.

From this analysis it is apparent that $\mathrm{PDGF}_{\mathrm{BB}}$ binds to plasticadsorbed TSP1 with approx. 10-60 times greater affinity than it does to soluble TSP1. One explanation for this finding is that the binding epitope on TSP1 for PDGF ${ }_{\mathrm{BB}}$ might be partly cryptic, and that denaturation of TSP1 on binding to plastic facilitates exposure of this epitope. This hypothesis has some support from the finding that change in TSP1 structure by intramolecular disulphide interchange also perturbs $\mathrm{PDGF}_{\mathrm{Bв}}$ binding (see below). However, this explanation must be treated with caution. The number of PDGF-binding sites on TSP1 cannot be determined from the competitive binding experiments shown in Figures 1 and 2. We have assumed that $1 \mathrm{~mol}$ of $\mathrm{PDGF}_{\mathrm{BB}}$ binds to $1 \mathrm{~mol}$ of TSP1, which might be an underestimate considering the homotrimeric structure of TSP1.

\section{Specificity of the PDGF ${ }_{\mathrm{BB}}-\mathrm{TSP} 1$ interaction}

To test the specificity of the $\mathrm{PDGF}_{\mathrm{BB}}-\mathrm{TSP} 1$ interaction, the effects of plasma proteins and other platelet $\alpha$-granule proteins 

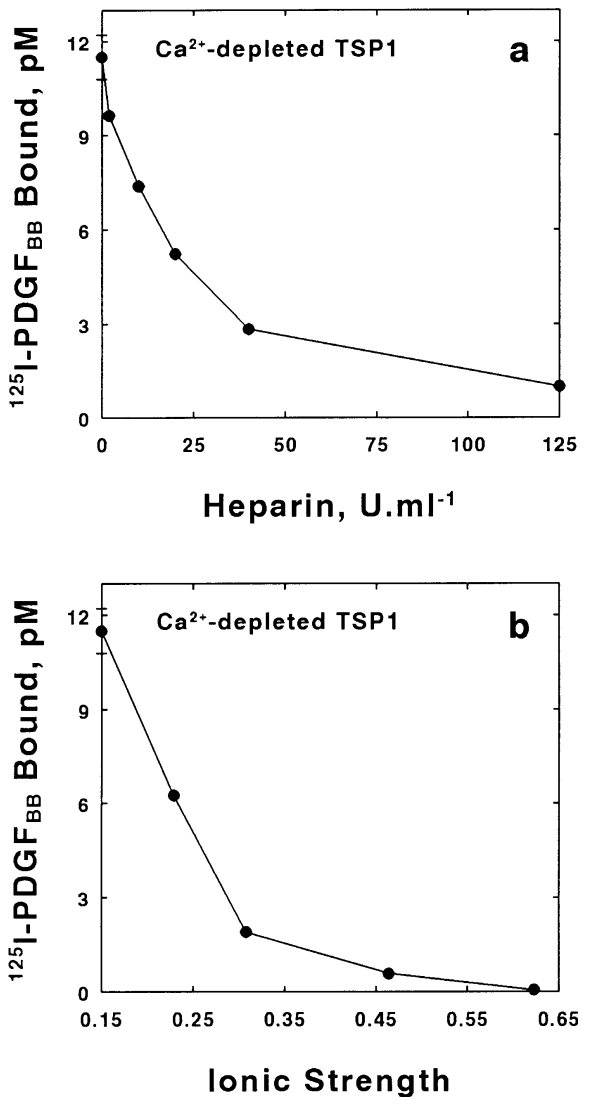

Figure 3 Effect of heparin and $\mathrm{NaCl}$ on binding of $\mathrm{PDGF}_{\mathrm{BB}}$ to TSP1

(a) Binding of ${ }^{125}$ - $\mathrm{PDGF}_{\mathrm{BB}}$ to $\mathrm{Ca}^{2+}$-depleted plastic-immobilized TSP1 as a function of heparin concentration. (b) Binding of ${ }^{125}$ - $-\mathrm{PDGF}_{\mathrm{BB}}$ to $\mathrm{Ca}^{2+}$-depleted plastic-immobilized TSP1 as a function of ionic strength, which was manipulated by increasing the $\mathrm{NaCl}$ concentration of the binding buffer. The total concentration of ${ }^{125}$-PDGF $_{B B}$ in the experiments shown in $(\mathbf{a})$ and $(\mathbf{b})$ was $50 \mathrm{pM}$.

on binding of ${ }^{125} \mathrm{I}_{-\mathrm{PDGF}}$ 을 to immobilized $\mathrm{Ca}^{2+}$-depleted TSP1 were measured. BSA, fibrinogen, $\beta$-thromboglobulin and platelet factor 4 , and at $100 \mathrm{nM}$ final concentration, did not significantly perturb the ${ }^{125} \mathrm{I}_{-\mathrm{PDGF}} \mathrm{BB}_{\mathrm{BB}}-\mathrm{TSP} 1$ interaction (results not shown). In contrast, soluble TSP1 at $100 \mathrm{nM}$ decreased the binding of ${ }^{125} \mathrm{I}_{-\mathrm{PDGF}}$ BB to immobilized TSP1 to $9 \%$ of control (Figure 2). $\alpha_{2}$-Macroglobulin is known to interact with $\mathrm{PDGF}_{\mathrm{BB}}$ with a dissociation constant of $100 \mathrm{nM}$ [36]. In accordance with this observation, we found that $100 \mathrm{nM} \alpha_{2}$-macroglobulin decreased the binding of ${ }^{125} \mathrm{I}_{-} \mathrm{PDGF}_{\mathrm{BB}}$ to immobilized TSP1 by $50 \%$, which indicated a dissociation constant of approx. $100 \mathrm{nM}$ (results not shown). Methylamine-activated $\alpha_{2}$-macroglobulin competed similarly to unactivated $\alpha_{2}$-macroglobulin (results not shown). $\mathrm{PDGF}_{\mathrm{AA}}$ and transforming growth factor $\beta$ at $40 \mathrm{nM}$ concentrations had no effect on binding of ${ }^{125} \mathrm{I}_{-\mathrm{PDGF}} \mathrm{BB}_{\mathrm{BB}}$ to immobilized TSP1 (results not shown). In contrast, soluble $\mathrm{PDGF}_{\mathrm{BB}}$ at $40 \mathrm{nM}$ concentration decreased the binding of ${ }^{125} \mathrm{I}-$ $\mathrm{PDGF}_{\mathrm{BB}}$ to immobilized TSP1 to $48 \%$ of control (Figure 1b).

Binding of ${ }^{125} \mathrm{I}_{-} \mathrm{PDGF}_{\mathrm{BB}}$ to immobilized $\mathrm{Ca}^{2+}$-depleted TSP1 was inhibited by heparin with a half-maximal effect at 20 i.u. $/ \mathrm{ml}$ (Figure 3a). This binding was also weakened by increasing ionic strength and was essentially ablated at 0.65 ionic strength (Figure $3 b)$. This implies that the interaction had a large ionic component.

It was expected that PDGF might remain associated with platelet TSP1 during its purification. However, no significant

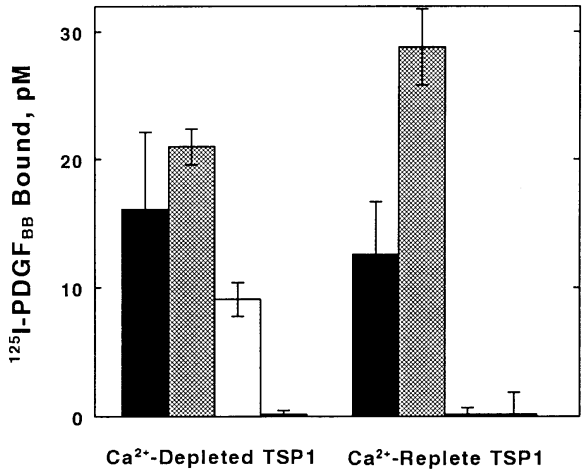

Figure 4 Effect of PDI-catalysed disulphide interchange in TSP1 on binding of ${ }^{125} \mathrm{I}-\mathrm{PDGF} \mathrm{BB}_{\mathrm{BB}}$

$\mathrm{Ca}^{2+}$-depleted or $\mathrm{Ca}^{2+}$-replete immobilized TSP1 was incubated with either buffer alone (filled bars), buffer containing GSH (hatched bars), buffer containing PDI (open bars), or buffer containing GSH and PDI (striped bars) for $60 \mathrm{~min}$ at $37^{\circ} \mathrm{C}$. The GSH and PDI concentrations were $0.7 \mathrm{mM}$ and $180 \mathrm{nM}$ respectively. Binding of ${ }^{125} / \mathrm{PDGF}_{\mathrm{BB}}$ to the treated TSP1 was measured as described in the Experimental section. The total concentration of ${ }^{125}{ }^{-}-\mathrm{PDGF}_{\mathrm{BB}}$ in the experiments was $75 \mathrm{pM}$ for $\mathrm{Ca}^{2+}$-depleted TSP1 and $150 \mathrm{pM}$ for $\mathrm{Ca}^{2+}$-replete TSP1. Results are means \pm S.E.M. for triplicate experiments.

PDGF contamination was observed in any of our TSP1 preparations. Bowen-Pope and Ross [37] described a sensitive receptor-binding assay for PDGF based on competition for binding of radiolabelled PDGF to cultured mesenchymal cells by unlabelled PDGF. Using this assay we estimated that our TSP1 preparations were contaminated with less than $0.01 \mathrm{ng}$ of PDGF per $\mu \mathrm{g}$ of TSP1 (results not shown). Western blotting of the TSP1 preparations with a polyclonal anti-PDGF ${ }_{\mathrm{BB}}$ antibody was also negative. These results imply that the majority of PDGF had dissociated and separated from platelet TSP1 during its purification.

\section{Effect of PDI-catalysed disulphide interchange in TSP1 on binding of PDGF $_{\mathrm{BB}}$}

The tertiary structure of TSP1 is regulated by intramolecular disulphide isomerization [38], which can be catalysed by PDI and GSH [29]. GSH is a cofactor for PDI. We tested whether PDGF binding was influenced by disulphide-dependent conformational changes in TSP1. Binding of ${ }^{125} \mathrm{I}_{-} \mathrm{PDGF}_{\mathrm{BB}}$ to $\mathrm{Ca}^{2+}$-depleted TSP1 was enhanced after incubation of either $\mathrm{Ca}^{2+}$-depleted or $\mathrm{Ca}^{2+}$-replete TSP1 with GSH alone (Figure 4). In contrast, binding was inhibited or ablated completely by incubation of either $\mathrm{Ca}^{2+}$-depleted or $\mathrm{Ca}^{2+}$-replete TSP1 with either PDI, or GSH and PDI (Figure 4).

\section{Binding of PDGF ${ }_{\mathrm{BB}}$ to its receptor on rat SMCs}

Binding of $\mathrm{PDGF}_{\mathrm{BB}}$ to $\mathrm{PDGF}$ receptor on cultured rat aortic SMCs was measured as described by Bowen-Pope and Ross [37]. Interaction of ${ }^{125}{ }^{-}-P_{D G F}$ with rat aortic SMCs is shown in Figure 5(a). To facilitate modelling of the data (see below), bound compared with total ${ }^{125}{ }^{2}-$ PDGF $_{\mathrm{BB}}$ was expressed in units of concentration. The usual units for bound ligand in receptorbinding studies are moles of ligand bound to a given number of cells. For comparison, 6 pM ${ }^{125}{ }^{-}-$PDGF $_{\mathrm{BB}}$ bound corresponds to $75 \mathrm{fmol}$ per $10^{6}$ cells.

The data in the absence of TSP1 were fitted to a single rectangular hyperbola by non-linear least-squares regression. The best fit gave a dissociation constant for interaction of 

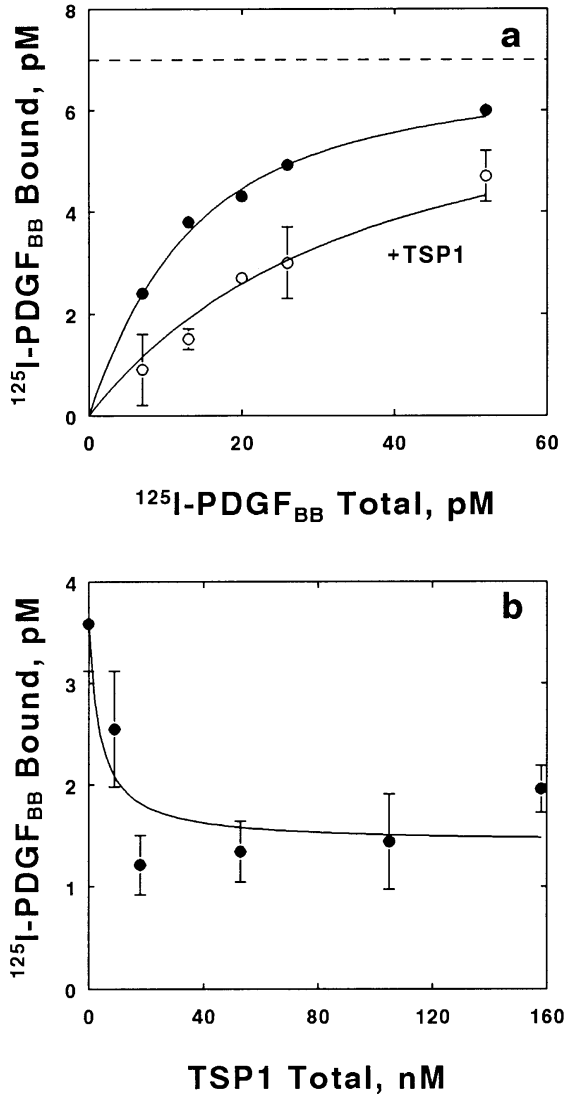

Figure 5 Effect of TSP1 on binding of PDGF $_{\mathrm{BB}}$ to PDGF receptor on rat aortic SMCs

(a) Binding of ${ }^{125}$-PDGF $_{\mathrm{BB}}$ to its receptor on rat aortic SMCs in the absence $(O)$ or presence of $\mathrm{Ca}^{2+}$-replete TSP1 $(\mathbf{O})$. TSP1 concentration was $105 \mathrm{nM}$. Data in the absence of TSP1 were fitted to a single rectangular hyperbola. The best-fit values were $K_{\mathrm{R}}=11 \pm 1 \mathrm{pM}$ and $[\mathrm{R}]_{0}=$ $7 \pm 2 \mathrm{pM}$. The broken line represents maximal binding of $7 \mathrm{pM}$. Data in the presence of TSP1 were fitted to eqn. (5) with fixed values of $K_{\mathrm{R}}=11 \mathrm{pM},[\mathrm{R}]_{0}=7 \mathrm{pM}$ and $\alpha=5$ [see (b)], with $K_{\mathrm{H}}$ the unknown parameter. The best fit value was $K_{\mathrm{H}}=15 \pm 5 \mathrm{nM}$. Results with error bars are means \pm S.D. for triplicate determinations. (b) Effect of $\mathrm{Ca}^{2+}$-replete TSP1 (O) on binding of ${ }^{125}$-PDGF $F_{B B}$ to its receptor on rat aortic SMCs. The total concentration of ${ }^{125}$-PDGF in the experiment was $13 \mathrm{pM}$. The solid lines represent the best fit of the data to eqn. (5). Data for TSP1 were fitted with fixed values of $K_{\mathrm{R}}=9 \mathrm{pM}$ and $[\mathrm{R}]_{0}=7 \mathrm{pM}$, with $K_{\mathrm{H}}$ and $\alpha$ the unknown parameters. The best-fit values were $K_{H}=2 \pm 2 \mathrm{nM}$ and $\alpha=5 \pm 2$. Results are means \pm S.D. for triplicate determinations for two separate experiments. To facilitate modelling of the data, bound against total ${ }^{125}-$ PDGF $_{B B}$ has been expressed in units of concentration. For comparison, $6 \mathrm{pM}^{125}{ }^{12}-\mathrm{PDGF}_{\mathrm{BB}}$ bound corresponds to $75 \mathrm{fmol}$ per $10^{6}$ cells.

PDGF $_{\mathrm{BB}}$ with its receptor on rat SMCs, $K_{\mathrm{R}}$, of $11 \pm 1 \mathrm{pM}$ and a total number of receptor-binding sites, $[\mathrm{R}]_{0}$, of $7 \pm 2 \mathrm{pM}$, which corresponds to a receptor number of $88 \mathrm{fmol}$ per $10^{6}$ cells. These values are the same as those reported by Bowen-Pope and Ross $[33,37]$. Unlabelled $\mathrm{PDGF}_{\mathrm{BB}}$ was also used to compete with radiolabelled $\mathrm{PDGF}_{\mathrm{BB}}$ for binding to rat aortic $\mathrm{SMC}$ (results not shown). Analysis of this competition isotherm gave $K_{\mathrm{R}}=9 \pm$ $3 \mathrm{pM}$ and $[\mathrm{R}]_{0}=7 \pm 1 \mathrm{pM}$, which are the same as the values calculated from the data of Figure 5(a).

\section{Effect of anti-TSP1 monoclonal antibody and TSP1 on binding of ${ }^{125}$ I-PDGF $_{\mathrm{BB}}$ to its receptor on rat SMCS}

The anti-TSP1 monoclonal antibody HB8432 partly inhibited the binding of ${ }^{125} \mathrm{I}_{-} \mathrm{PDGF}{ }_{\mathrm{BB}}$ to its receptor on rat aortic SMCs (results not shown). Binding was decreased to $63 \%$ of control and the extent of inhibition was maximal at $100 \mu \mathrm{g} / \mathrm{ml}$ monoclonal antibody. An irrelevant monoclonal antibody against bovine liver PDI had no effect on the binding of ${ }^{125} \mathrm{I}_{-} \mathrm{PDGF}_{\mathrm{BB}}$ to its receptor. We used $\alpha_{2}$-macroglobulin, a known $\mathrm{PDGF}_{\mathrm{BB}^{-}}$ binding protein that prevents $\mathrm{PDGF}_{\mathrm{BB}}$ from interacting with its receptor [36], as an internal control for these experiments. $\alpha_{2}$ Macroglobulin inhibited $\mathrm{PDGF}_{\mathrm{BB}}$ binding to its receptor on rat SMCs with half-maximal effect at $140 \mathrm{nM}$, which is similar to the value (approx. $100 \mathrm{nM}$ ) reported by Raines et al. [36] (results not shown).

We expected that binding of TSP1 to PDGF ${ }_{\mathrm{BB}}$ would influence interaction of $\mathrm{PDGF}_{\mathrm{BB}}$ with its receptor on rat SMCs. $\mathrm{Ca}^{2+}$ replete TSP1 non-competitively inhibited the binding of $\mathrm{PDGF}_{\mathrm{BB}}$ to its receptor (Figure 5). The data of Figures 5(a) and 5(b) were fitted to the non-competitive inhibition binding model shown in Scheme 1 and described by eqn. (5). The data in Figure 5(b) were fitted by using fixed values of $K_{\mathrm{R}}(9 \mathrm{pM})$ and $[\mathrm{R}]_{0}(7 \mathrm{pM})$ (see above), with the dissociation constant for interaction of ${ }^{125} \mathrm{I}$ PDGF $_{\mathrm{BB}}$ with TSP1 $\left(K_{\mathrm{H}}\right)$ and $\alpha$ as the unknown parameters. The best-fit values were $K_{\mathrm{H}}=2 \pm 2 \mathrm{nM}$ and $\alpha=5 \pm 2$. This value for $K_{\mathrm{H}}$ is comparable with the value determined for the interaction of the purified proteins, $32 \pm 5 \mathrm{nM}$ (Table 1).

Data from Figure 5(a) in the presence of TSP1 were fitted by using fixed values of $K_{\mathrm{R}}(11 \mathrm{pM})$ and $[\mathrm{R}]_{0}(7 \mathrm{pM})$ and assuming $\alpha=5$ (from Figure $5 \mathrm{~b}$ ), with $K_{\mathrm{H}}$ as the unknown parameter. The best-fit value was $K_{\mathrm{H}}=15 \pm 5 \mathrm{nM}$, which is comparable with the estimate of this parameter from the results of Figure 5(b) $(2 \pm 2 \mathrm{nM})$ and the value determined from competitive binding assays with purified proteins $(32 \pm 5 \mathrm{nM}$; Table 1$)$. The general agreement in estimates of the fitted parameters from the results of Figures 2 and 5 validate the non-competitive inhibition model proposed to account for the data. However, it should be emphasized that this is the simplest binding model that accounted for the data. Other, more complicated, binding models could also be envisaged that are not excluded by our results.

\section{DISCUSSION}

TSP1 has been shown to play an important role in PDGFmediated proliferation and migration of cultured SMCs $[23,24]$. The mechanism by which TSP1 promotes PDGF activity is not understood but it is apparent that TSP1 must interact with the SMC surface to be active. We hypothesized that binding of PDGF to TSP1 on the SMC surface might be a means by which TSP1 enhances PDGF function. We now report that PDGF bound tightly and specifically to TSP1 and that this interaction was markedly dependent on the disulphide bond conformation of TSP1. Also, binding of PDGF ${ }_{\mathrm{BB}}$ to TSP1 did not preclude $\mathrm{PDGF}_{\mathrm{BB}}$ from binding to its receptor on rat aortic SMCs.

TSP1 functions in vivo bound to cell surfaces or to extracellular matrix, and there is evidence that the conformation of TSP1 bound to cells or matrix resembles that of the form used in these studies, that is TSP1 purified in buffers containing $0.1 \mathrm{mM} \mathrm{Ca}^{2+}$. We have shown that the anti-TSP1 monoclonal antibodies D4.6 and A65M interact with this form of TSP1 bound to plastic or extracellular matrix, but not with TSP1 purified in buffers containing $2 \mathrm{mM} \mathrm{Ca}^{2+}$ [39]. Antibody D4.6 immunostained TSP1 in the extracellular matrix and on the surface of cultured fibroblasts and SMCs [40] (L. J. Matthias and P. J. Hogg, unpublished work), and antibodies D4.6 and A65M immunostained blood vessel walls and occasional matrix cells in human rheumatoid synovial tissue [39]. Moreover, antibody A65M was developed against TSP1 in endothelial cell extracellular matrix [41], implying that the form of TSP1 used in these studies is 
produced by endothelial cells. Importantly, Majack et al. [23] showed that antibodies (D4.6 and A6.1) specific for TSP1 purified in $0.1 \mathrm{mM} \mathrm{Ca}{ }^{2+}$-containing buffers are effective in inhibiting PDGF-mediated SMC proliferation.

The observation that cell-surface TSP1 is essential for rat aortic SMC proliferation [23] suggested that the binding of $\mathrm{PDGF}_{\mathrm{BB}}$ to TSP1 on the surface of SMC might participate in the interaction of $\mathrm{PDGF}_{\mathrm{BB}}$ with its receptor. We have shown that anti-TSP1 monoclonal antibodies partly inhibited the binding of labelled PDGF $_{\mathrm{BB}}$ to its receptor on rat SMCs, and added TSP1 non-competitively inhibited the binding of labelled $\mathrm{PDGF}_{\mathrm{BB}}$ to rat SMCs. In other words, PDGF ${ }_{\mathrm{BB}}-\mathrm{TSP} 1$ complexes bound to PDGF receptor but with $1 /(5 \pm 2)$ times the affinity shown by uncomplexed $\mathrm{PDGF}_{\mathrm{BB}}$. This non-competitive inhibition by TSP1 is in contrast with other PDGF-binding proteins, $\alpha_{2}$-macroglobulin [36] and SPARC [42], which competitively inhibit the binding of PDGF to its receptor.

An important question is what consequences does binding of $\mathrm{PDGF}_{\mathrm{BB}}$ to TSP1 have for the activity of $\mathrm{PDGF}_{\mathrm{BB}}$ ? There are similarities between the $\mathrm{PDGF}_{\mathrm{BB}}-\mathrm{TSP} 1-\mathrm{PDGF}$ receptor interactions described herein and the fibroblast growth factor (FGF)-glycosaminoglycan-FGF receptor interactions [43]. Cellsurface glycosaminoglycans have been shown to enhance the binding or targeting of FGF to its signalling receptor, probably by decreasing the dimensionality of FGF diffusion from three dimensions in the extracellular space to two dimensions at the cell surface [43]. When restricted to diffusion in two dimensions on the cell surface, FGF is more likely to encounter and bind to its less abundant high-affinity signalling receptors. The net effect is an increase in the local concentration of FGF at the cell surface, which greatly enhances chances of interaction with highaffinity FGF receptors. TSP1 produced by SMCs binds to the SMC surface and extracellular matrix $[11,23]$. It is plausible that $\mathrm{PDGF}_{\mathrm{BB}}-\mathrm{TSP} 1$ interactions result in high local concentrations of $\mathrm{PDGF}_{\mathrm{BB}}$ in the vicinity of or at the cell surface, which will enhance the interaction of $\mathrm{PDGF}_{\mathrm{BB}}$ with its signalling receptors. Another similarity between the FGF-glycosaminoglycan and $\mathrm{PDGF}_{\mathrm{BB}}-\mathrm{TSP} 1$ interactions is their ionic nature (Figure 3), which usually implies rapid dissociation rates. In contrast, highaffinity signalling receptors such as the FGF and PDGF receptors are often characterized by rapid on-rates and slow off-rates $[33,43]$.

The binding of $\mathrm{PDGF}_{\mathrm{BB}}$ to TSP1 was initially an unexpected observation as two other investigators had reported that $\mathrm{PDGF}_{\mathrm{BB}}$ and TSP1 do not interact. Raines et al. [42] reported that radiolabelled $\mathrm{PDGF}_{\mathrm{BB}}$ did not interact with TSP1 bound to nitrocellulose, and Yabkowitz et al. [24] reported that radiolabelled PDGF $_{\text {вв }}$ did not co-immunoprecipitate with PDGF. A possible explanation for these seemingly conflicting observations is the finding that $\mathrm{PDGF}_{\mathrm{BB}}$ does not bind to $\mathrm{Ca}^{2+}$-replete TSP1 purified in buffers containing $2 \mathrm{mM} \mathrm{Ca}^{2+}$ (P. J. Hogg, unpublished work). Yabkowitz et al. [24] used this non-binding form of TSP1 in their studies, which might account for their negative result. Raines et al. [42] did not indicate their source of TSP1 so this comparison cannot be made. Therefore the findings reported herein and those of Raines et al. [42] and Yabkowitz et al. [24] are not necessarily contradictory. These results highlight the structural lability of TSP1 and the necessity to consider this when studying the functions of this protein.

Disulphide isomerization in TSP1 might be a means by which certain functions of TSP1 are regulated [12,29,39,44-46]. We have shown that PDI catalyses disulphide interchange in TSP1 that markedly changes the affinity of binding of cathepsin $G$ and anti-TSP1 monoclonal antibodies $[29,39]$ and PDGF $_{\mathrm{Bв}}$ (Figure 4) to TSP1. PDI was recently demonstrated on the platelet surface
$[47,48]$ and we have found that PDI is present on the surface of rat aortic SMCs in an 'active' reduced conformation (L. J. Matthias and P. J. Hogg, unpublished work). It is therefore plausible that catalysis of disulphide interchange in TSP1 by cellsurface PDI might be a mechanism that controls the binding of $\mathrm{PDGF}_{\mathrm{BB}}$ to TSP1.

In conclusion, the findings herein imply that binding of $\mathrm{PDGF}_{\mathrm{BB}}$ to TSP1 might assist in the targeting of PDGF ${ }_{\mathrm{BB}}$ to its receptor on SMCs, which might explain why cell-surface TSP1 is important for PDGF-mediated proliferation and migration of vascular SMCs. Binding of PDGF $_{\mathrm{BB}}$ to TSP1 might have other consequences, such as protecting $\mathrm{PDGF}_{\mathrm{BB}}$ from proteolytic inactivation. Further understanding of this system will be aided by determining the binding site on TSP1 and $\mathrm{PDGF}_{\mathrm{BB}}$ and vice versa, as specific perturbation of the $\mathrm{PDGF}_{\mathrm{BB}}-\mathrm{TSP} 1$ interaction would help to elucidate the significance of this interaction of $\mathrm{PDGF}_{\mathrm{BB}}$ function.

We thank Dr. Peter Little for the gift of rat aortic SMCs. This work was supported by the National Heart Foundation of Australia and the National Health and Medical Research Council of Australia.

\section{REFERENCES}

1 Ross, R. (1987) Annu. Rev. Med. 38, 71-79

2 Heldin, C. H. (1992) EMBO J. 11, 4251-4259

3 Khachigian, L. M. and Chesterman, C. N. (1992) Pathology 24, 280-290

4 Khachigian, L. M. and Chesterman, C N. (1993) Platelets 4, 304-315

5 Ross, R. (1993) Nature (London) 362, 801-809

6 Lahav, J. (1993) Biochim. Biophys. Acta 1182, 1-14

7 Bornstein, P. and Sage, E. H. (1994) Methods Enzymol. 245, 62-85

8 Bornstein, P. (1995) J. Cell Biol. 130, 503-506

9 Jaffe, E. A., Ruggiero, J. T., Leung, L. L., Doyle, M. J., McKeown-Longo, P. J. and Mosher, D. F. (1983) Proc. Natl. Acad. Sci. U.S.A. 80, 998-1002

10 Mosher, D. F., Doyle, M. J. and Jaffe, E. A. (1982) J. Cell Biol. 93, 343-348

11 Majack, R. A., Cook, S. C. and Bornstein, P. (1985) J. Cell Biol. 101, 1059-1071

12 Sun, X., Skorstengaard, K. and Mosher, D. F. (1992) J. Cell Biol. 118, 693-701

13 Li, W.-X., Howard, R. J. and Leung, L. L. K. (1993) J. Biol. Chem. 268, 16179-16184

14 McKeown-Longo, P. J., Hanning, R. and Mosher, D. F. (1984) J. Cell Biol. 98, 22-28

15 Yabkowitz, R. and Dixit, V. M. (1991) Cancer Res. 51, 3648-3656

16 O'Shea, K. S., Liu, L.-H. J., Kinnunen, L. H. and Dixit, V. M. (1990) J. Cell Biol. 111, 2713-2723

17 Iruela-Arispe, M. L., Liska, D. J., Sage, E. H. and Bornstein, P. (1993) Dev. Dynam. 197, 40-56

18 Reed, M. J., Puolakkainen, P., Lane, T. F., Dickerson, D., Bornstein, P. and Sage, E. H. (1993) J. Histochem. Cytochem. 41, 1467-1477

19 Clezardin, P., Frappart, L., Clerget, M., Pechoux, C. and Delmas, P. D. (1993) Cancer Res. 53, 1421-1430

20 Wight, T. N., Raugi, G. J., Mumby, S. M. and Bornstein, P. (1985) J. Histochem. Cytochem. 33, 295-302

21 Raugi, G. J., Mullen, J. S., Bark, D. H., Okada, T. and Mayberg, M. R. (1990) Am. J. Pathol. 137, 179-185

22 Framson, P. and Bornstein, P. (1993) J. Biol. Chem. 268, 4989-4996

23 Majack, R. A., Goodman, L. V. and Dixit, V. M. (1988) J. Cell Biol. 106, 415-422

24 Yabkowitz, R., Mansfield, P. J., Ryan, U. and Suchard, S. J. (1993) J. Cell. Physiol. 157, 24-32

25 Murphy-Ullrich, J. E. and Mosher, D. F. (1985) Blood 66, 1098-1104

26 Murphy-Ullrich, J. E., Schultz-Cherry, S. and Höök, M. (1992) Mol. Biol. Cell 3, 181-188

27 Jakobsen, E. and Kierulf, P. (1973) Thromb. Res. 3, 145-159

28 Porath, J., Carlsson, J., Olsson, I. and Belfrage, G. (1975) Nature (London) 258, 598-599

29 Hotchkiss, K. A., Chesterman, C. N. and Hogg, P. J. (1996) Biochemistry 35, 9761-9767

30 Oslon, S. T., Bock, P. E. and Sheffer, R. (1991) Arch. Biochem. Biophys. 286, 533-545

31 Hogg, P. J., Owensby, D. A., Mosher, D. F., Misenheimer, T. M. and Chesterman, C. N. (1993) J. Biol. Chem. 268, 7139-7146

32 Little, P. J., Cragoe, E. J. and Bobik, A. (1986) Am. J. Physiol. 251, C707-C712 
33 Bowen-Pope, D. F. and Ross, R. (1995) Methods Enzymol. 109, 69-100

34 Nichol, W. L., Ward, L. D. and Winzor, D. J. (1981) Biochemistry 20, 4858-4860

35 Hogg, P. J. and Winzor, D. J. (1984) Arch. Biochem. Biophys. 234, 55-60

36 Raines, E. W., Bowen-Pope, D. F. and Ross, R. (1984) Proc. Natl. Acad. Sci. U.S.A. 81, 3424-3428

37 Bowen-Pope, D. F. and Ross, R. (1982) J. Biol. Chem. 257, 5161-5171

38 Speziale, M. V. and Detwiler, T. C. (1990) J. Biol. Chem. 265, 17859-17867

39 Matthias, L. J., Gotis-Graham, I., Underwood, P. A., McNeil, H. P. and Hogg, P. J. (1996) Biochim. Biophys. Acta 1296, 138-144

40 Dixit, V. M., Galvin, N. J., O'Rourke, K. M. and Frazier, W. A. (1986) J. Biol. Chem. 261, 1962-1968
41 Underwood, P. A., Steele, J. G., Dalton, B. A. and Bennett, F. A. (1990) J. Immunol. Methods 127, 91-101

42 Raines, E. W., Lane, T. F., Iruela-Arispe, M. L., Ross, R. and Sage, E. H. (1992) Proc. Natl. Acad. Sci. U.S.A. 89, 1281-1285

43 Schlessinger, J., Lax, I. and Lemmon, M. (1995) Cell 83, 357-360

44 Misenheimer, T. M. and Mosher, D. F. (1995) J. Biol. Chem. 270, 1729-1733

45 Hogg, P. J. (1994) Thromb. Haemost. 72, 787-792

46 Hogg, P. J., Owensby, D. A. and Chesterman, C. N. (1993) J. Biol. Chem. 268 21811-21818

47 Chen, K., Detwiler, T. C. and Essex, D. W. (1995) Br. J. Haematol. 90, 425-431

48 Essex, D. W., Chen, K. and Swiatkowska, M. (1995) Blood 86, 2163-2173

Received 20 January 1997/21 April 1997; accepted 7 May 1997 